\title{
The dorsal neve of the clitoris in relation to urinary incontinence sling procedures
}

Sonè van der Walt, ${ }^{1,2}$ Frans J. van Wijk, ${ }^{3}$ Zeelha Abdool, ${ }^{4}$ Anna C. Oettlé ${ }^{1}$

${ }^{1}$ Department of Anatomy, School of Medicine, Faculty of Health Sciences, University of Pretoria, Gauteng, South

Africa,

${ }^{2}$ Department of Anatomy, School of Pathology and Pre-clinical sciences, Faculty of Health Sciences, Sefako

Makgatho Health Sciences University, Gauteng, South Africa,

${ }^{3}$ Department of Urology, Urology Hospital, Pretoria, Gauteng. South Africa, ${ }^{4}$ Consultant Obstetrician and

Gynecologist, University of Pretoria, Gauteng, South Africa

*Correspondence to: S. van der Walt, Department of Anatomy, School of Medicine, Faculty of Health Sciences, University of Pretoria, Private Bag x323, Arcadia, Pretoria, 0007, Republic of South Africa. Tel: +27 833128485 . Email: duplessis.son@gmail.com

Running head: Dorsal nerve of the clitoris in sub-urethral procedures

Conflict of interest: The authors declare that they have no conflict of interest

S van der Walt: Project development, Data Collection, Manuscript writing

FJ van Wijk: Performance of procedures, Manuscript revision for scientific and factual content

Z Abdool: Performance of procedures

AC Oettlé: Project development, Supervision

Three different slings were used in this study, the TVT and TVT-O slings, donated by one company and the TOT slings donated by a second company.

This work was presented at the following conferences/workshops:

ESAU (Expertise in South African Urology), Pretoria, Gauteng, South Africa, 21 September 2013

$\mathbf{4 2}^{\text {nd }}$ Annual Congress of the Anatomical Society of Southern Africa, Stellenbosch, Western Cape, South Africa, 13-16 April 2014

Earth Medical and AMS Urology workshop, Pretoria, Gauteng, South Africa, 20 June 2014

Earth Medical and AMS Urology workshop, Cape Town, Western Cape, South Africa, 22 June 2014 


\begin{abstract}
Introduction To avoid injury to the perineal branches of the pudendal nerve (PN) during urinary incontinence sling procedures, a thorough knowledge of the course of these nerves is essential. The dorsal nerve of the clitoris (DNC) may be endangered when performing the retropubic (tension-free vaginal tape) procedure as well as the inside-out and outside-in transobturator tape procedures. The purpose of this study was to identify the anatomical relationships of the DNC to the tapes placed during the procedures mentioned and to determine the influence of body variations.
\end{abstract}

Methods The cadaver body mass index (cBMI) [weight $(\mathrm{kg}) /$ length $\left(\mathrm{m}^{2}\right)$ ] was determined on unembalmed cadavers. Sub-urethral tape procedures were performed by a registered urologist and gynecologist on a sample of 15 females; six retropubic, seven inside-out and nine outside-in transobturator tapes were inserted. After embalmment, dissections were completed and distances measured between the DNC to the tapes placed.

Results In general the trajectory of the outside-in tape was closer to the DNC than with the other tapes. A weak and non-significant correlation was found between the cBMI and the distance between the trajectory of the inside-out tape and the tension-free vaginal tape, but not the outside-in tape to the DNC.

Conclusion The findings suggest that the inside-out tape is less likely to injure the DNC as compared to the outside-in procedure, regardless of the cBMI. Future studies on larger samples will be desirable to verify these findings. 
Keywords: body mass index, pudendal nerve, retropubic tape, transobturator tape

Summary The dorsal nerve of the clitoris was found to be closer to the outside-in tape than the inside-out tape regardless of cadaveric BMI.

\section{Introduction}

Thorough knowledge of the course and branching pattern of the pudendal nerve (PN) is indispensable to prevent injury to these nerves during the performance of urinary incontinence sling procedures. The following sub-urethral tape procedures have been associated with injury to the dorsal nerve of the clitoris (DNC) and were considered in this study [1-5]: the outside-in transobturator tape (TOT); inside-out transobturator tape (TVT-O) and tension-free vaginal tape/retropubic tape (TVT).

The retropubic tension-free vaginal tape was the first suburethral tape procedure introduced in 1996 by Ulmsten et al [6]. As a result of various complications [7-11], the outside-in transobturator procedure was developed in 2001 by Delorme [12] in an attempt to decrease bladder, bowel and neurovascular injuries. In 2003 De Leval [13] modified the outside-in procedure in women to an inside-out approach.

Following transobturator surgery, patients will sometimes present with transient or long standing symptoms of perineal pain or hypersensitivity and dyspareunia. The association of these symptoms with involvement of the DNC might not be recognized and therefore underreported by surgeons. Entrapment of the DNC, after tensioning of the tapes, against the inferior pubic ramus as the nerve courses along the posteromedial border of the inferior pubic 
ramus may possibly be responsible for dyspareunia. Injury to the DNC, along the medial border of the inferior pubic ramus has been implied by Delorme et al [14] and may influence postoperative sexual function. However, studies on sexual functioning after mid-urethral sling placement have not been conclusive $[15,16]$.

Various researchers and clinicians concluded that a higher rate of thigh and perineal pain existed in the group undergoing a transobturator tape, compared to those undergoing a retropubic sling $[1,17]$. Pudendal neuropathic pain associated with indirect nerve compression due to incorrect placement of the tapes has also been described $[1,17]$.

High BMI was found to be more frequently associated with the occurrence of urinary incontinence $[18,19]$ and therefore possibly more likely to be in need of a sub-urethral tape procedure, no studies could be found in the literature demonstrating variance in outcome of these procedures with BMI.

The aim of this study was to identify anatomical relationships to each performed procedure by measuring distances between the closest points of the DNC and to the tapes placed. The influence of cadaveric body mass index (cBMI) on these measurements was noted.

As the transobturator needles follow opposite trajectories, the authors hypothesize that the needles will pass further from the DNC during the inside-out procedure, but closer to the DNC during the outside-in procedure, rendering entrapment of the nerve more likely. These distances may increase or decrease with increasing CBMI. The null hypothesis were that there were no difference between the distances from the DNC to the sub-urethral tapes placed and the $\mathrm{CBMI}$ had no correlation with these distances. 


\section{Materials and methods}

The study was conducted at the University of Pretoria, Department of Anatomy and was approved by the Student Ethics Committee of the University of Pretoria (S56/2012, approved June 25,2012$)$. Selected sub-urethral tape procedures were performed by a registered urologist and gynecologist on a sample of 15 females (ages 20-89 years) from African and European descent. Six retropubic tapes were placed according to the technique introduced by Ulmsten et al [6]. Seven inside-out transobturator tapes were inserted according to the technique described by de Leval [13] and nine outside-in transobturator tapes were placed according to the technique described by Ridgeway et al [20]. The TVT and TVT-O slings that were inserted were donated by one company and the TOT slings were donated by a second company. It was thus inserted dependent on availability. Figure 1 indicates the trajectory of the needles inserted to place various tapes to the DNC. 

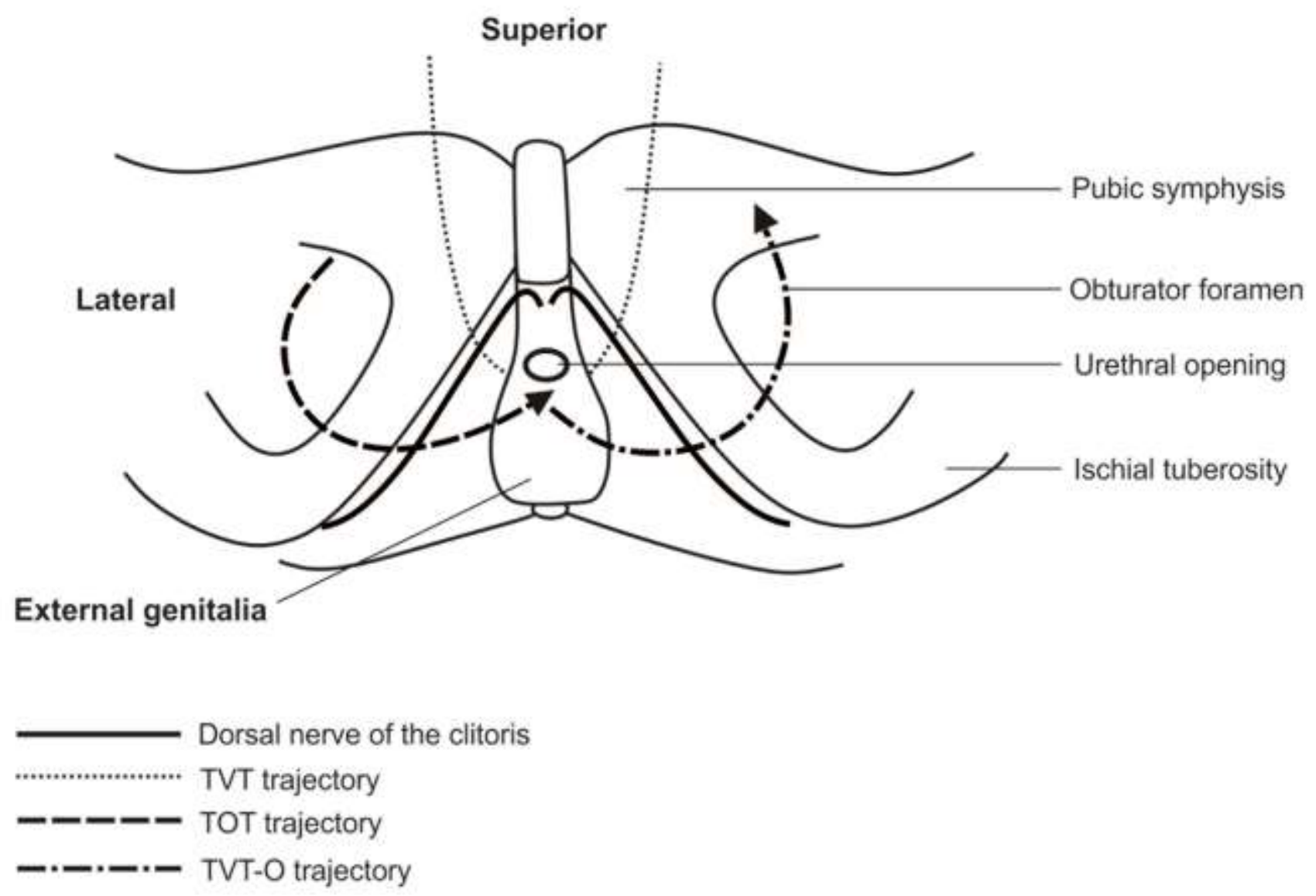

Figure 1. Trajectory of the transobturator and retropubic trocar needles in transobturator sling placement

Dissections were performed on embalmed cadavers placed in the lithotomy position on the right side. Shrinkage and swelling of cadaver tissue were considered minimal as dissections were performed in a contained area.

Skin and fat were removed to visualize the area from the labia majora to the obturator area where the tapes exited. The ischiocavernosus muscle was reflected inferiorly to visualize the medial border of the inferior pubic ramus and to find the DNC related to the posteromedial border of the ramus. Blunt dissection was carried out to determine the position of the tapes 
placed. Measurements were taken between the closest distances from the DNC to the tapes inserted. Linear regressions were performed to indicate the influence of $\mathrm{cBMI}$ on the distances between the DNC to the various sub-urethral tapes placed. One-way ANOVA tests were performed to determine statistical differences between the distances from the DNC to the various tapes placed existed. ANOVA tests were also done to indicate if significant differences existed between the 3 groups

The $\mathrm{CBMI}$ [weight $(\mathrm{kg}) /$ length $(\mathrm{m})^{2}$ ] was calculated using the length and weight of the cadavers, which were measured upon arrival of the unembalmed bodies at the university. The correlation of the $\mathrm{cBMI}$ on the measurements (between the DNC to the tapes placed) was determined.

\section{Results}

The distances measured between the closest points of the DNC to the mesh tape placed were noted for each embalmed cadaver and the basic statistical analysis is represented in Table 1. Differences in the bony frame between the African and European cadavers were not taken into account as the sample was too small to perform statistical analysis on the individual groups.

It was evident that the outside-in tape (figure 2) was often closer to the DNC than the insideout (figure 3) tapes placed. The mean distance between the inside-out tape and the DNC was $17.81 \mathrm{~mm} \pm 5.18 \mathrm{~mm}$ and from the outside-in tape to the DNC, $14.64 \mathrm{~mm} \pm 7.71 \mathrm{~mm}$. 
Table 1. cBMI and distances (in $\mathrm{mm}$ ) between the DNC to the tapes inserted

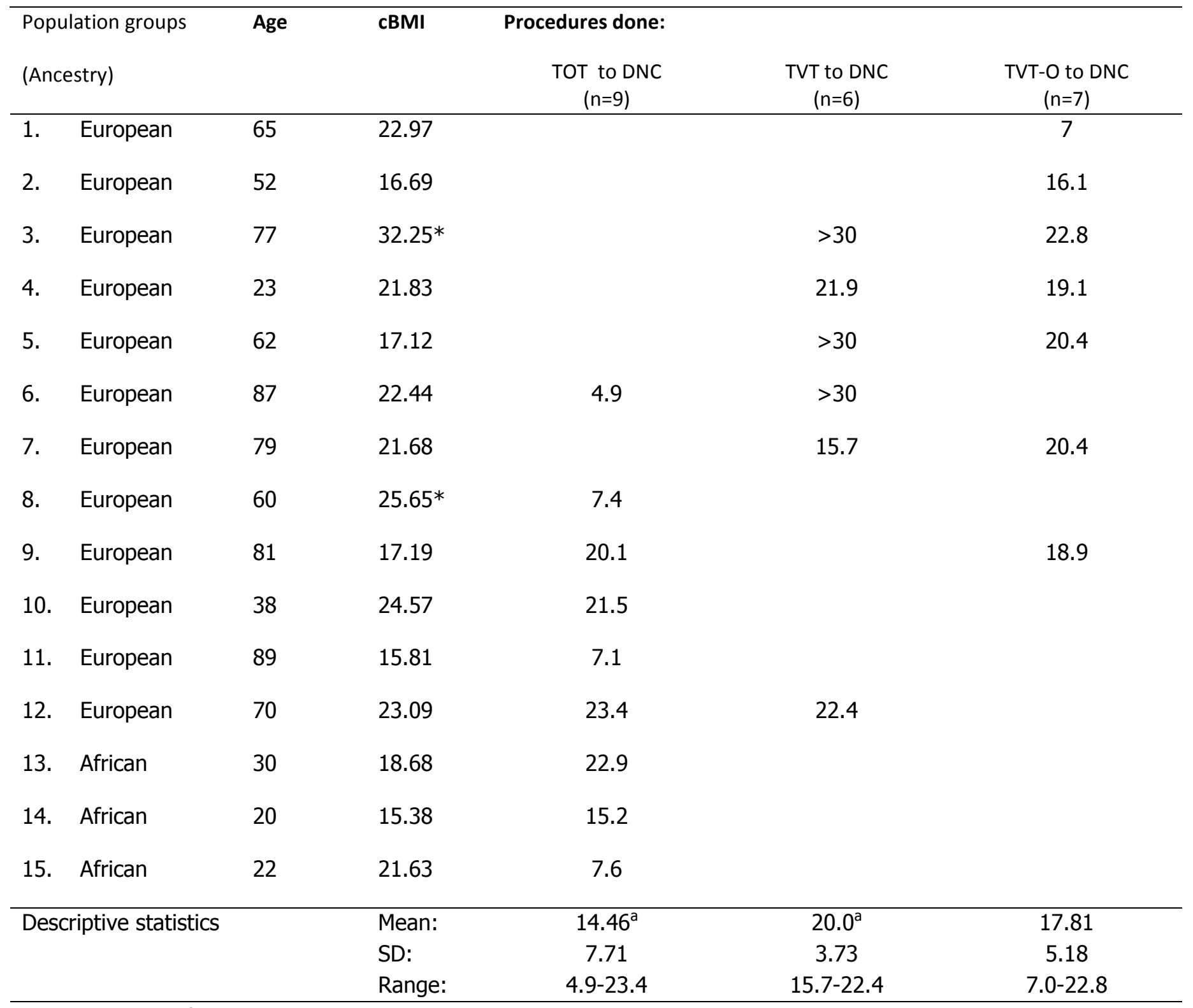

$\mathrm{A} c \mathrm{BMI} \geq 25.5 \mathrm{~kg} / \mathrm{m}^{2}$ is indicated by a $*$ (high cBMl to obese group). The sample size is indicated by the $\mathrm{n}$ value

${ }^{a}$ : indicates a statistical significant difference between groups $(p=0.0177)$ 


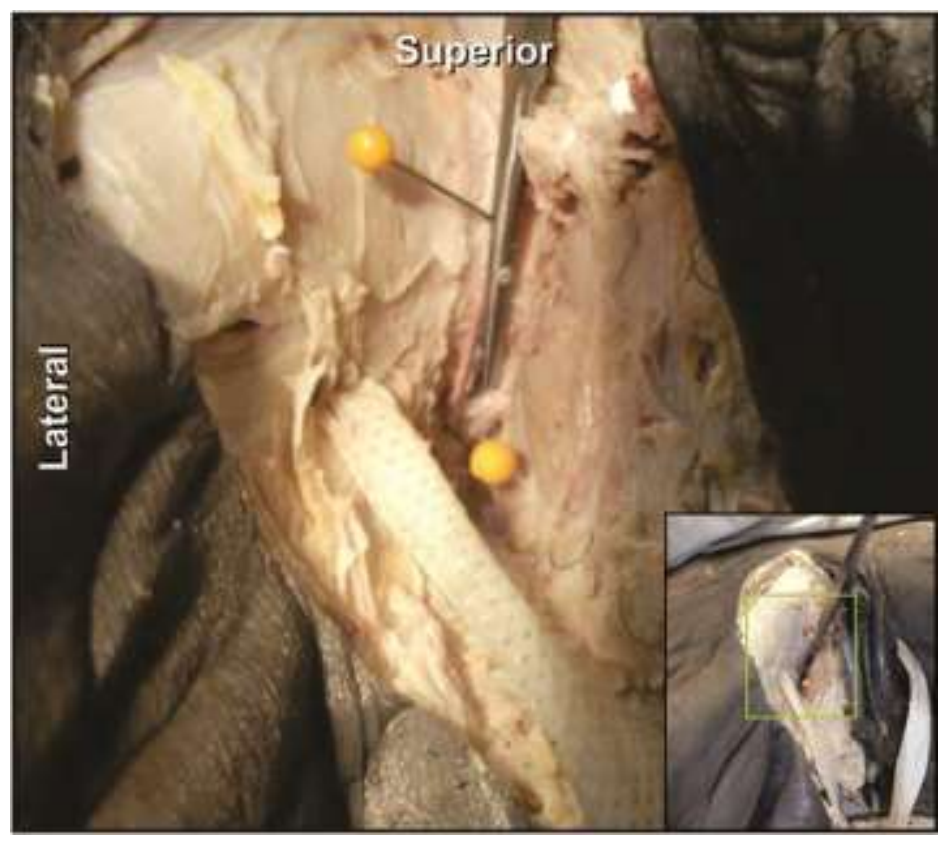

Figure 2. Distance between the dorsal nerve of the clitoris and the outside-in tape.

Orange pins indicates the dorsal nerve of the clitoris.

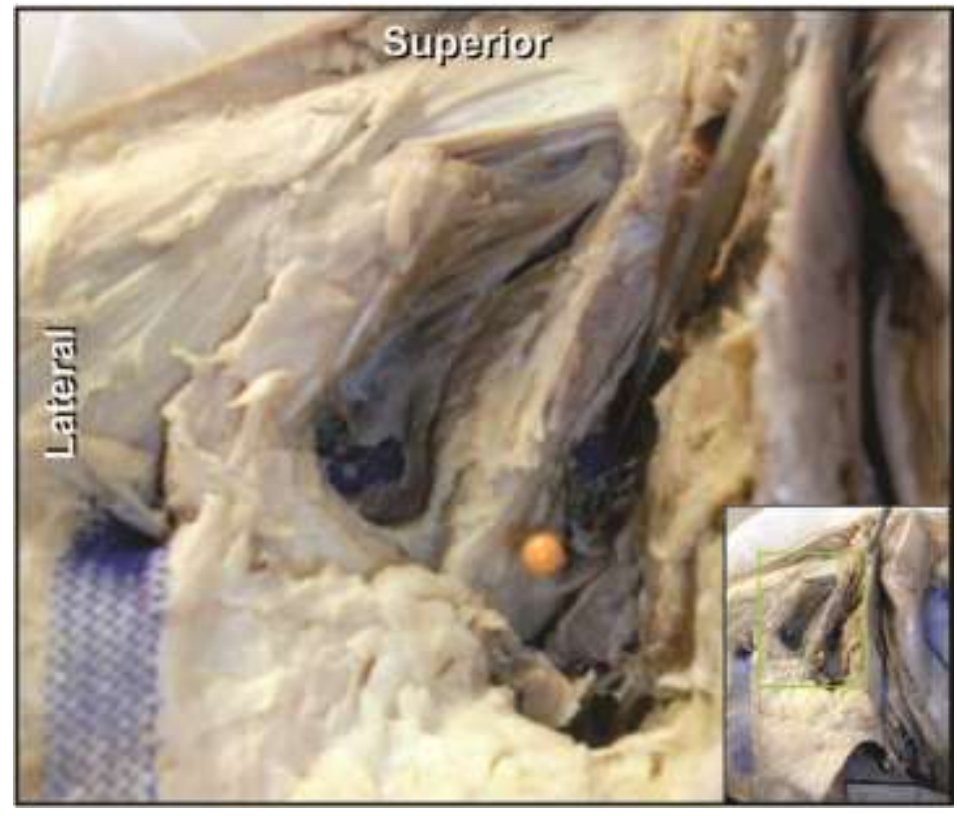

Figure 3. Distance between the dorsal nerve of the clitoris and the inside-out tape.

Orange pins indicates the dorsal nerve of the clitoris. 
In the retropubic tape cases the trocar needle passed more than $30 \mathrm{~mm}$ from the DNC in three of the six cases and in this way kept a clear distance from it. For the remaining three cases, the distance between the DNC and the retropubic sling had a mean value of $20 \mathrm{~mm} \pm 3.73 \mathrm{~mm}$. The one-way ANOVA test showed a statistical significant difference between the TOT to DNC as compared to the TVT to DNC distance $(p=0.0177)$. The significant differences could be even more pronounced, as some of the values exceeded $30 \mathrm{~mm}$, but $30 \mathrm{~mm}$ was used to perform statistical analysis.

Most $(8 / 15)$ of the females had a normal cBMI $\left(18.6-25 \mathrm{~kg} / \mathrm{m}^{2}\right)$, five had a low CBMI $(\leq 18.5$ $\left.\mathrm{kg} / \mathrm{m}^{2}\right)$ and two were classified as obese $\left(\geq 25 \mathrm{~kg} / \mathrm{m}^{2}\right)$. When performing an Ordinary least squares regression, no significance were found between the $\mathrm{CBMI}$ to the distances from the

DNC to the tapes placed. A weak negative correlation $\left(r=-0.06\right.$ and $\left.r^{2} 0.00\right)$ existed between CBMI and the distance from the TOT to DNC. A weak positive correlation $\left(r=0.20\right.$ and $\left.r^{2}=0.04\right)$ existed between the $\mathrm{cBMI}$ and the distance from the TVT to DNC, and lastly, a weak positive correlation ( $r=0.18$ and $\left.r^{2}=0.03\right)$ existed between the cBMI and the distance from the TVT-O to DNC. This study found that there were no statistical significant differences in the distance between the DNC and the tapes placed.

\section{Discussion}

The outcomes of this study imply that the TVT procedure is least likely to injure the DNC than the other tapes placed. The inside-out transobturator sling appear to be further from the DNC than those placed by the outside-in route, although not statistically significant, regardless of BMI. Achtari et al. [21] also found no statistical difference between the TOT and TVT-O 
procedures when the distances between the tapes and the DNC were measured. The distance between the tape and the DNC was $11 \pm 3 \mathrm{~mm}$ and $12 \pm 4 \mathrm{~mm}$ in the TVT-O and TOT procedures respectively. In this study, the distances between the TVT-O and TOT procedures were $17.81 \pm$ $5.18 \mathrm{~mm}$ and $14.46 \pm 7.71 \mathrm{~mm}$ respectively. The authors speculate that these differences could be due to variations in the bony pelvis, as research has shown that differences exist between black and white individuals. [20, 22, 23]

Delmas [24] inserted transobturator tapes in ten French female cadavers. The DNC was described to lie close to the inferior pubic ramus. He speculated that the pudendal nerve branches could be damaged while trying to locate the inferior border of the obturator foramen during the inside-out procedure. When these techniques are performed correctly, no neurovascular structures should be damaged. This statement corresponds to results found by a study performed by Montoya et al. [25]. They describe the position of the dorsal nerve of the clitoris in relation to the perineal membrane. As the nerve courses superficial to the perineal membrane and the needle passes deep to the membrane, the tape should remain some distance from the nerve [25].

Keeping a safe distance from the DNC might not always be as simple, as the performance of these procedures is dependent on the experience of the operator. It is well known that the bony framework of the pelvis differs amongst individuals, populations and with stature. Several authors have found that individuals of African ancestry have a smaller pelvic bony frame and also a narrower ischiopubic ramus which could render the PN branches more exposed. On the 
other hand, standard needles designed for European population groups, could endanger these nerves. $[20,22,23]$.

An interesting observation, that needs further investigation, was observed regarding BMI. It was noted that the distance between the outside-in tape and the DNC decreased with increasing $\mathrm{CBMI}$, while the distance between the inside-out tape and the DNC increased with increasing $\mathrm{CBMI}$.

The findings of this study suggest that the TVT procedure is the least likely to injure the DNC whereas the inside-out tape could be safer than the outside-in procedure, regardless of the BMI of the patient.

Limitations of this study included dissections to determine the distance from the retropubic tape to the perineal branches, deep to the levator ani muscle were not performed. Differences in the bony frame between the African and European cadavers were not taken into account as the sample was too small to perform statistical analysis on the groups individually. Dissections were only carried out on the right side as these cadavers were also used in the training of medical students. This study should be reproduced on a bigger sample size to produce accurate reflections of the influence of $\mathrm{BMI}$ on the distances between tapes placed and the DNC.

\section{Conflicts of interest: None.}




\section{References}

1. Rigaud J, Pothin P, Labat JJ, et al. Functional results after tape removal for chronic pelvic pain following tension-free vaginal tape or transobturator tape. J Urol. 2010;184(2):6105.

2. Bondili A, Cooper J. Pudendal neuralgia: A rare cause of pain after tension free vaginal tape. J Obstet Gynaecol. 2011;31(5):454-5.

3. Vervest HA, Bongers MY, van der Wurff AA. Nerve injury: an exceptional cause of pain after TVT. Int Urogynecol J. 2006;17(6):665-7.

4. Cho MK, Kim CH, Kang WD, et al. Complications following Outside-in and Inside-out Transobturator-Tape procedures with Concomitant Gynecologic operations. Chonnam Med J. 2011;47(3):165-9.

5. Paulson JD, Baker J. De novo pudendal neuropathy after TOT-O surgery for stress urinary incontinence. JSLS. 2011;15(3):326.

6. Ulmsten $U$, Henriksson $L$, Johnson $P$, et al. An ambulatory surgical procedure under local anesthesia for treatment of female urinary incontinence. Int Urogynecol J. 1996;7(2):816.

7. Nilsson CG, Kuuva N, Falconer C, et al. Long-term results of the tension-free vaginal tape (TVT) procedure for surgical treatment of female stress urinary incontinence. Int Urogynecol J. 2001;12(8):5-8. 
8. Farrell S, Beckerson L, Epp A, et al. Tension-free vaginal tape (TVT) procedure. J Obstet Gynaecol Can. 2003;25(8):692-4.

9. Okorocha I, Jwarah E, Jackson S. Surgery for urinary incontinence. Reviews in Gynaecological Practice. 2005;5(4):251-8.

10. Lee KS, Choo MS, Lee YS, et al. Prospective comparison of the 'inside-out' and 'outsidein' transobturator-tape procedures for the treatment of female stress urinary incontinence. Int Urogynecol J. 2008;19(4):577-82.

11. Ulmsten $U$, Falconer $C$, Johnson $P$, et al. A multicenter study of tension-free vaginal tape (TVT) for surgical treatment of stress urinary incontinence. Int Urogynecol J. $1998 ; 9(4): 210-3$

12. Delorme E. Transobturator urethral suspension: mini-invasive procedure in the treatment of stress urinary incontinence in women. Progres en urologie: journal de I'Association francaise d'urologie et de la Societe francaise d'urologie. 2001;11(6):1306.

13. De Leval J. Novel surgical technique for thetreatment of female stress urinary incontinence: transobturator vaginal tape inside-out. Urology. 2003;44:724-30.

14. Delorme E, Droupy S, de Tayrac R, Delmas V. Transobturator Tape (Uratape ${ }^{\circledR}$ ): A New Minimally-Invasive Procedure to Treat Female Urinary Incontinence. Eur Urol. 2004;45(2):203-7. 
15. Maaita M, Bhaumik J, Davies A. Sexual function after using tension-free vaginal tape for the surgical treatment of genuine stress incontinence. BJU Int. 2002;90(6):540-3.

16. Pauls RN, Silva WA, Rooney CM, et al. Sexual function after vaginal surgery for pelvic organ prolapse and urinary incontinence. Am J Obstet Gynecol. 2007;197(6):622. e1 e7.

17. Latthe PM, Foon R, Toozs-Hobson P. Transobturator and retropubic tape procedures in stress urinary incontinence: a systematic review and meta-analysis of effectiveness and complications. BJOG. 2007;114(5):522-31.

18. Mommsen S, Foldspang A. Body mass index and adult female urinary incontinence. World J Urol. 1994;12(6):319-22.

19. Danforth KN, Townsend MK, Lifford K, Curhan GC, Resnick NM, Grodstein F. Risk factors for urinary incontinence among middle-aged women. Am J Obstet Gynecol. 2006;194(2):339-45.

20. Ridgeway BM, Arias BE, Barber MD. Variation of the obturator foramen and pubic arch of the female bony pelvis. Am J Obstet Gynecol. 2008;198(5):546. e1 - e4.

21. Achtari C, Mckenzie BJ, Hiscock R, et al. Anatomical study of the obturator foramen and dorsal nerve of the clitoris and their relationship to minimally invasive slings. Int Urogynecol J. 2006;17(4):330-4.

22. Patriquin M, Loth S, Steyn M. Sexually dimorphic pelvic morphology in South African whites and blacks. HOMO. 2003;53(3):255-62. 
23. Patriquin M, Steyn M, Loth S. Metric analysis of sex differences in South African black and white pelves. Forensic Sci Int. 2005;147(2):119-27.

24. Delmas V. Anatomical risks of transobturator suburethral tape in the treatment of female stress urinary incontinence. Eur Urol . 2005;48(5):793-8.

25. Montoya TI, Calver L, Carrick KS, Prats J, Corton MM. Anatomic relationships of the pudendal nerve branches. Am J Obstet Gynecol. 2011;205(5):504. e1 - e5. 